\title{
Delay model for Engineering Procurement Construction (EPC): a case of Liquefied Natural Gas (LNG) projects in Indonesia
}

\author{
Peter F. Kaming ${ }^{1, *}$, Ambrosius Koesmargono ${ }^{1}$, and Bimo Wahyu Aji ${ }^{1}$ \\ ${ }^{1}$ Department of Civil Engineering, Universitas Atma Jaya Yogyakarta, Yogyakarta, Indonesia
}

\begin{abstract}
Development of Liquefied Natural Gas (LNG) projects in Indonesia mostly utilized Engineering Procurement Construction) EPC as type of contract. The contract is particularly applied in large-scale project such as LNG because it needed to be realized with comprehensively planning and to be on time, and on budget for the benefit for all stakeholders. In maximizing the utilization of the resources, LNG plant project depended on detailed work plans and tightly work schedule. This research aims at analyzing factors influencing causes of project delay in construction LNG projects. Data were collected using survey method by mean of distributing questionnaire to respondent that representing skilled staffs of the contractor LNG construction. Grouping variables were carried out using factors analysis, and the generated factors and delay of the projects then were analyzed their relationship using Structural Equation Modelling (SEM). Results of this study generated seven factors that influenced the delay of the EPC contract in LNG projects. The factors are: Human Resources; Management; Material; External; Plant Equipment; Method; Quality. From the result of SEM analysis it generated a model for analyzing the delay of the EPC for LNG projects in Indonesia.
\end{abstract}

\section{Introduction}

Liquefied natural gas (LNG) is natural gas that has been converted to liquid form for ease and safety of nonpressurized storage or transport. The liquefaction process involves removal of certain components, such as dust, acid gases, helium, water, and heavy hydrocarbons, which could cause difficulty downstream. A typical LNG process. The gas is first extracted and transported to a processing plant where it is purified by removing any condensates such as water, oil, mud, as well as other gases. An LNG process train will also typically be designed to remove trace amounts of mercury from the gas stream to prevent mercury amalgamation with aluminium in the cryogenic heat exchangers. The gas is then cooled down in stages until it is liquefied. LNG is finally stored in storage tanks and can be loaded and shipped [1]. Natural gas is mainly converted in to LNG to achieve the natural gas transport over the seas where laying pipelines is not feasible technically and economically such as Indonesia of a maritime nation that covers over 14000 islands. LNG achieves a higher reduction in volume than compressed natural gas $(\mathrm{CNG})$ so that the (volumetric) energy density of LNG is 2.4 times greater than that of $\mathrm{CNG}$ (at 250 bar) or 60 percent that of diesel fuel. This makes LNG cost efficient in marine transport over long distances. However, CNG carrier can be used economically up to medium distances in marine transport. Specially designed cryogenic sea vessels used as LNG carriers or cryogenic road tankers are used for its transport. LNG is principally used for transporting natural gas to markets, where it is distributed as pipeline natural gas. It can be used in natural gas vehicles, although it is more common to design vehicles to use compressed natural gas. Its relatively high cost of production and the need to store it in expensive cryogenic tanks have hindered widespread commercial use [1].

Energy consumption in Indonesia is expected to increase because of population and economic growth. The presidential decree of 2006 formulated by the government of Indonesia has aimed at reducing petroleum dependency and promoting natural gas use in the context of diversification of energy sources. However Indonesia doesn't have sufficient pipelines for transport of natural gas. Location of gas pipelines is limited to Java and Sumatra islands. Also Indonesia has many islands. Hence infrastructure for transporting natural gas to remote islands is very limited. Consequently, there are many diesel generators in power plants, factories and smelters in remote areas. For example, the number of diesel power generators in remote areas in Indonesia operated by PLN is 4,500 units with total capacity of 2,500 MW [2].

The government of Indonesia has recently introduced a new policy for supplying LNG to domestic market instead of exporting. This policy change will result in the supply of natural gas for domestic market through LNG

*Corresponding author: peterkaming82@gmail.com 
and increase quota of natural gas from the production for domestic market. Eventually, the decentralized distribution system of LNG to remote island areas would be developed. For example, PT Pertagas Niaga and the association of natural gas distributors of PT Pertagas Niaga is conducting feasibility study to transport LNG by ISO containers from Bontang to locations of end users. Considering high dependency of remote island areas on diesel fuel, there is a very big potential for introducing mini-LNG distribution system for remote areas. It would lead to conversion of fuel from petroleum products to natural gas and installation of cogeneration system using natural gas. Such applications of LNG would result in reduction of fuel cost, energy saving and reduction of $\mathrm{CO} 2$ by considerable amount. See report of Nomura Research Institute [2].

The Liquefied Natural Gas (LNG) project is a largescale development project, in particular in the field of development for production plant, normally involved state-owned firms or multi-national corporations. The project serves to produce gas to a liquid involves various aspects of construction such as Engineering Procurement Construction (EPC). In the implementation of the project, construction division plays a major role for the success of the project in implementation of LNG plant construction, the implementation of this project involves various of expertizes, working at some primary divisions included: engineer, mechanical, electrical, instrument, piping, painting, civil and building, insulation, health safety environment and security (HSES). In addition, the project also involved the secondary divisions such as procurement, finance, Human resources, administration. Following the completion of the project, it continues to proceed to maintenance process. The commissioning division that ensures the successful in the achievement of mechanical work of each packet, and carried out testing for operability of LNG project. In the implementation stage of LNG construction work, it depends heavily on the results of the commissioning test. Success the implementation of the work depends on the overall availability of resources, methods of work, management of its implementation arrangements. When the source is inadequate, it would affect workers productivity, and consequently resulting in delays in project implementation. Delay in construction is a major problem faced in the construction world for general, and also LNG plant projects in particular. In most construction projects, delays would bring some impacts to the extension of the duration, from several days to even in years. Delay in construction is generally understood as a critical factor to execution of project implementation in the aspect of time, cost and quality as specified.

The objectives of this study are: 1) to analyse the dominant factors influencing delay of LNG plant construction project; 2) to develop a model relationship between Management factors, External factors, Human Resources, Material factor, Quality factor, Method factor, factor Plant Equipment to predict Delay.

This study is elaborated with the limitations of the problem addressed based on the following explanation: 1) this study is limited to the search for inhibiting factors completion of the LNG project; 2) Data of the LNG projects were those have been built from the year 2010$2014 ; 3$ ) the respondents in this study were implementing officers working LNG project.

\section{Literature Reviews}

\subsection{Construction Delay}

Projects were often experiencing delays. It could even be worse since there were almost $80 \%$ of the projects are experiencing delays [3]. Project delays could often repeatedly occurred on the affected works as well as by the influencing factors. Frequent of work delays from planned schedules could be caused by several variables, it could also be due to internal or external factors that occurred accidentally. In other words, delays often occurred either predictable or unpredictable. Construction projects are said to be successful if they can be completed on a timely basis as on scheduled, within budget, according to desired specifications and to obtain satisfaction from interested stakeholders involved in the projects. See Majid \& McCaffer, [4].

There are two categories that can determine as follows: 1). Non-Excusable Delay is an error that occurs solely because of the actions, negligence or mistakes of the project owner $[4,5,6]$. Starting from when to be completed and how the project will be done and how to provide resources. The delays may appear to underestimate productivity, improper project planning and scheduling, poor management and supervision, incorrect construction methods, unreliable equipment damage, subcontractors or suppliers. Project plans and project schedules always refer to the conditions of assumptions and forecasts that existed at the time the plans and schedules were made, hence the problem will arise in the event of a mismatch between estimates and assumptions with actual reality [4]. The common impact that often happens is the delay in project execution time. 2). An Excusable Delay is a delay caused by events beyond the control of either the owner or the contractor. It is divided into two types: a) unsatisfactory delays (noncompensable delay) Delay caused by third parties or incidents beyond the control of either the owner or the contractor or not caused by either party $[5,6]$. Such as usually include actions that occur on God's will, unusual weather, strikes, fires, government actions in his capacity and others $[4,5,6]$; and b) delay eligible for compensation. Delay can be caused by the government regulation, negligence or error of the project owner $[5,6]$. This would usually lead to an extension of the schedule or the timing of the completion of the required schedule, which would result in a changed cost or budget, being claimed by the contractor or the owner $[4,5]$.

There are five common causes and the subject of delays: poor management situations and oversight, unexpected soil conditions, length of action in decision making involving all project teams, varied clients, and variations of work required. Kumaraswamy \& Chan [7] grouped the causes of delay into the following: 1). Factors involved in the project include project characteristics, variations required, communication between the various 
parties, the speed of decision making involving all project teams, and soil conditions. 2). Client related factors include those relating to client characteristics, project financing, variations and requirements, and interim payments to contractors. 3). Factors related to the design include the design of the team experience, the complexity of the design project, and the errors and delays in producing the design document. 4). Related contractor factors include contractor experience in project planning and control, site management and oversight, subcontract rates, and overall cash flow. 5). Factors related to the material include material deficiencies, material changes, procurement programming, and off-site production prefabricated. 6). Labour-related factors include shortages of labour, low skill levels, weak motivation, and low productivity. 7). Plant factors or related equipment include deficiencies, low efficiency, malfunction and incorrect choice. 8). External factors include waiting time for approval from the description of material test samples and environmental problems and restrictions

Sugiharto and Hampton [8] studied on construction delays in a number of projects in Jakarta. Their studied based of empirical studies to large and small contractors on delay during the construction stage. Similar delay studies carried out in India [9] and Malaysia [10,11].

\subsection{Structural Equation Model for Delay Analysis}

Structural equation modelling The basic concept and SEM tools are called in the literature as an upcoming structural covariance analysis, modelling structure of covariance, and analysis of covariance structures [8], can used to describe the relationship between two types of variables, i.e. observed (measured directly) and latent (indirectly measured). SEM allows analysis to determine what factors underlie a set of indicators; it is also possible to examine the strength of the relationship between theoretical constructs [12]. The SEM method involves two procedures; namely, the components of measurement and structural components [13]. The component measurement determines how the latent variable is measured from the observed variable. The structural component reveals the relationship between the latent variables. See Islam and Faniran [14]. Major applications of SEM include causal modelling (or path analysis), confirmatory factor analysis, second order factor analysis, regression model, covariance structure model, and structure model correlation [15]. For path analysis, the analysis is based on a hypothetical procedure of causal relationships between variables and testing of causal models with systems of linear equations. This research uses path analysis for research problem model. To help analyse the implementation of SEM to solve problems, computer software systems have been widely developed, such as EQS (Multivariate Software Inc., Encino, California), LISREL (Scientific Software International). See Santoso [16]

\section{Methodology}

\subsection{Variable Causing Delay}

The research method is a scientific way to get data with a specific purpose and usefulness. In this section of the paper, the things that will be conveyed in the following steps: thinking framework, data collection techniques, data types/variables collected, methods and data collection instruments, data analysis techniques, parameters and weighting. The variables of the study provide an interrelated model and how big the level of influence can be used with SEM method. There are: material, delay, plant, equipment, human, method, resources, external, management, and quality.

\subsection{Data Collection Techniques}

In this study, the sample is the LNG project implementer who had been involved in the project directly during 2010 to 2014 in the area of the LNG construction project. Sample collection in this study was conducted randomly, and for sub group with small population number (service use) which was done by taking all respondents with amount of 40 respondent respectively. LNG project implementers (40 Respondents) samples taken i.e. LNG project manager (site manager/field manager) and supervisory/management consultant (site manager and field supervisor) who has carried out the work and has handled the supervision of the LNG construction project. The data in this study is quantitative data, i.e. data collected and processed to find or obtain how big the factors that hinder the completion of LNG construction project.

\subsection{Types of Data / Variables Collected}

The data of variables collected in the analysis of factorfactor factors causing delays in the LNG construction projects are as follows: 1). Respondent's data. It comprises of personal information collected to distinguish the respondent's background regarding types of company they were currently working such as Contractors group, Subcontractors, Vendor, or Client. 2). Project data. They were collected to identify the project profile of the respondent whether or not it status regarding delay. Data could be from historical projects which took place from 2010 to 2014 based on the experience practitioners working at LNG with type of Engineering Procurement Constructions (EPC) contract. 3) Data of common factors are taken from the journal and opened sources. This data were obtained based on perceptions of respondents from implementers who are directly involved in the implementation process of LNG construction EPC projects from 2010 to 2014 . Key indicators of risk factors that affect project delays. 


\subsection{Factors Attributes/Indicators, Code and References of The Studied Variables}

\subsubsection{Material variables}

Materials Low quality of material M1; Shortage of material in the Market M2; Changes in material types and specifications during the construction M3; Delay in material delivery M4; Damages to the material in transport and storages M5; Manufacturing difficulties of Special materials M6; Idle time of material M7; Shortage in construction materials M8; Damage sorted materials while they are needed urgently M9; Poor quality of materials M10; Unclear specification M11. See Dolage and Rathnamali [17], Shanmugapriya, and Subramanian [18], and Parath, et.al [19].

\subsubsection{Human resources variables}

Human resources Unavailability of experienced technical staff Scarcity of skill labour HR1; Shortage of labour HR2; Labour injuries, disputes HR3; Labour strikes HR4; Personal conflicts among labour HR5; Complication of hire Local persons HR6; Absenteeism of labour HR7; Lack of skill of labour HR8; Unqualified work force team HR9; Shortage of experienced staff and Labour HR10; Lack of sub-contractor skill HR11. See Dolage and Rathnamali [17], Haseeb et.al [20]; Parath et.al [19]; Shanmugapriya, and Subramanian, [18].

\subsubsection{Plant equipment variables}

Plant Equipment Low productivity and efficiency of equipment PE1; Disruption of Accessories (SCAR) PE2; Poor maintenance of Equipment PE3; Operational Testing discharge area (Pneumatic test and commissioning test) PE4; Availability of equipment PE5; Complication of advanced technology equipment PE6; Transportation of equipment PE7. See Dolage and Rathnamali [17]; Parath et.al [19].

\subsubsection{Method Variables}

Method Procedure permit M1; SIMOPS M2; Safety procedure M3; Commissioning Area During Construction M4; Improper Construction Methods Implemented M5; Proportion of offsite Prefabrication M6; Wrong installation package M7. See Dolage and Rathnamali [17], Parath. et.al [19], and Chai and Yusof [21].

\subsubsection{Management Variables}

Management Top management support MG1; Close communication between management MG2; Lack of communication MG3; Poor Communication and Coordination MG4; Poor site management and Supervision MG5; Specified sequence of completion, i.e. Staged completion MG6; Job assignment MG7; Project control Management MG8; Top management support MG9; Commitment to project MG10; Lack of motivation MG11; Frequent project meeting MG12.
See Garbharran, et.al [22], Parath et,al. [19]; Doloi,et.al. [23,24]; and Chai and Yusof [21].

\subsubsection{External Variables}

External Weather EX1; Unpredictable Weather conditions EX3; Project location EX4; Local conflict (War, rebellion or insurrection) EX5. Parath et.al [19], Government law EX2, Yang and $\mathrm{Ou}$ [25]

\subsubsection{Quality Variables}

Quality High quality of work required Q1; Rework Q2; Appliances Defects Q3; Handover Packaging Q4; Delay in Performing Inspection and Testing Q5. See Chai and Yusof [21].

\subsubsection{Delay variables}

Delay Human related D1; Method related D2; External related D3; Management related D4; and Quality related D5. See Yang and Qu [25].

\subsection{Data Collection Method}

Data were obtained from the questionnaire would be used to analyse with the right method. Data collection from different types of questionnaires would be analysed and responded with the purpose of the research questionnaire in the convey directly to the respondents who have professionals at EPC project work Especially in LNG, This primary data will be in use to capture the data that will be analysed.

\subsection{Composition of Questionnaire}

Questionnaires are a way of generating feelings, beliefs, experiences, perceptions, or attitudes of some individual samples. A questionnaire survey planned based on research objectives. A questionnaire survey developed to obtain respondents' opinions on the problem construction delays. Questionnaires are classified into 4 sections: 1). Section A requested background of respondents being related to general information for respondents. 2). Section $\mathrm{B}$ asked the assessing the delay of a project is measured by the quantity or percentage of the project and see from what part of the project in the construction is often delayed. 3). Section $C$ contains of delays with probability and delay values in a project adopted from Yang and $\mathrm{Qu}$ [26]. The variables in the questionnaire column are the factors causing the delay in the construction project included with the value of influence on a scale of 1 to 5 While for filling the delayed column data based on the percentage using the delay rate scale as follows: Very high $80-100 \%$ weighted 5; High $60-80 \%$ weighted 4; Enough $40-60 \%$ weighted 3; Low 20 to $40 \%$ are weighted 2; and Very Low $0-20 \%$ is weighted 1.4). Section D contains a number of opened questions. This section provides the opportunities for the respondent to suggest how delay in LNG project can be overcome. 


\section{Results and discussion}

\subsection{Analysis of personal data}

Stages of collecting data for prior to the testing phase by collecting questionnaires, questionnaires have been spread to various parties who have experience in the field of EPC LNG in particular. The results of questionnaire data collection obtained 40 respondents consist of Client 2 persons as $5 \%$, EPC Contractor 36 persons as $90 \%$, and others is 2 persons as $5 \%$.

Respondent based on their experienced working in LNG projects were: 1 ) $<5$ Years is 11 persons as $27.5 \%$; 2) $5-10$ Years is 6 persons as $15 \%$; 3 ) $11-15$ Years is 3 persons as $7.5 \%$; 4) more than 15 Years is 20 person as $50 \%$. Respondent based on their position in organization: 1) Manager is 13 persons consisted of Commissioning, Field engineer, QAC, Site Manager, Mechanical Engineer. 2) Superintendent is 4 persons working at Insulation, Mechanical, Electrical, Piping. 3) Deputy 2 persons working as Superintendent, Site Manager, Mechanic Engineer. 4) Engineer is 4 person consisted of Field Engineer, Piping Engineer. 5) QC is 5 persons working at QC Department, QC Civil Structure, and Insulation. 6) Chief coordinator has 11 persons working as Cost Control. 7) HSE 1 Officer.

Respondent based on involvement in working at a number of LNG projects as follows: 1) 1 - 3 Projects has 11 persons as $27.50 \%$; 2) $4-6$ Projects has 4 persons as $10.00 \%$; 3$) 7$ - 9 Projects has 1 person as $2.50 \%$; 4) More than 9 Projects has 24 person with $60.00 \%$. Respondents experiencing of Delay at LNG projects based on Estimated Project Duration to total durations as follows: 1) $0-5 \%$ has 5 persons as $12.50 \%$;2) $5 \%-10 \%$ has 5 persons as $12.50 \%$; 3) $10 \%-15 \%$ has 11 person as $27.50 \%$; 4) more than $20 \%$ has 19 persons as $47.50 \%$.

Respondents based on experiencing with the Number of Project Delay as follows: 1) 1 - 3 Projects has 18 persons as $45,00 \%$; 2) 4 - 6 Projects has 7 persons as $17,50 \%$; 37 - 9 Projects has 5 persons as $12,50 \%$; 4) more than 9 Projects has 10 persons as $25,00 \%$. Respondent based on state of the schedule and operational project mostly delaying groups of works as follows: 1) Instrument / electrical, none of person respond to this work; 2) Mechanical has 1 person as $2.5 \%$; 3) Piping has 36 persons as $90 \%$; and 4) Commissioning has 3 persons as $7.5 \%$. The most commonly occurring condition of working groups delay was the piping division (90\%). The piping work is a job that has a high working interfaces with other divisions, and it has interconnected and main work that often results in delaying the overall progress of the $\mathrm{LNG}$ project. Delays can have a major impact on job completion as well as rework, commissioning work groups occupies second as the cause of delay as $7.5 \%$. Respondent based on State of The Schedule And Operational Project On Times in Working groups as follows: 1) Instrument/electrical has 6 person as $15 \%$;2) Mechanical has 28 persons as $70 \%$; 3 ) Piping 1 person as $2.50 \%$; and 4) Commissioning has 5 persons as $12.50 \%$. Implementation of timely EPC LNG project in
Mechanical division showed majority $70 \%$ compared to the division working groups.

\subsection{Factor Analysis}

Data processing is done using statistics application program data processing is analysed using principal components technique. The extraction of insignificant variables will be extracted with analysing factor that eliminates the value that $<0.5$ anti-image, and proceed with the value that $>0.5$ anti-image. Communalities more than 0.5 on variable of questionnaire data are applied. The test result on delay factor on EPC LNG projects are as follows:

1). Principal Independent Factor. This test consists of the percentage of delay obtained from questionnaire data faced by respondents.

2). Principal Dependent Factor. Inter-dependent Variable PC test results showed that the underlying anti-image output as the dependent factor. As it also shows that the test results, Anti-Image of the material variable shows the anti-image data from M1 to M11. It shows that all variable in diagonal of the matrix is above 0.5 implying that the result is a significant value.

\subsection{Confirmatory Factory Analysis (CFA)}

This tool is used to test the measurement model, with this tool will be known whether existing indicators are really can explain a construct. By doing CFA, it can be an indicator is deemed not to be strongly influential or able explains a construct in particular the SEM model construct factor delays. Why this is done because in order to get the process good modelling to analyse SEM, i.e. correlation test confirmatory factor analysis (CFA) in the results can be through the test likelihood extracted to all dependent latent variables shown on Table 1 . Performed with 4 iterations from 64 indicators to 10 indicators, for dependent factors as shown in Table 1.

Performed with 4 iterations from 64 indicators to 10 indicators, for dependent factors as follows. Indicators Problem of Materials, Human Resource, Management, and Quality of the Maximum Likelihood Extraction Attributes/Indicators Material (Factor 1).

Performed with 4 iterations from 64 indicators to 10 indicators, for dependent factors as follows. Indicators Problem of Materials, Human Resource, Management, and Quality of the Maximum Likelihood Extraction Attributes/Indicators Material (Factor 1).

Table 1. Pattern Matrix Results from Likelihood Extracted

\begin{tabular}{|l|l|l|l|}
\hline Factors & Quality & Resource & Management \\
\hline M2 & & 0.764 & \\
\hline M3 & & 0.740 & \\
\hline M9 & & 0.849 & \\
\hline HR1 & & 0.556 & \\
\hline HR9 & & 0.559 & \\
\hline Q2 & 0.879 & & \\
& & & \\
\hline
\end{tabular}




\begin{tabular}{|l|l|l|l|}
\hline Factors & Quality & Resource & Management \\
\hline Q3 & 0.881 & & \\
\hline Q4 & 0.829 & & \\
\hline MG5 & & & 0.769 \\
\hline MG7 & & & 0.681 \\
\hline
\end{tabular}

Shortage of material in the market M2 $=0.764$. Resource-changes in material types and specifications during the construction M3=0.740. Damage sorted materials while they are needed urgently M9 $=0.849$. Unavailability of experienced technical staff Scarcity of skill labourers HR $1=0.556$. Unqualified work force team HR9 $=0.559$.

Factor 2 Attributes/Indicators Management: Poor site management and supervision MG5 $=0.769$. Job assignment $\mathrm{MG} 7=0.681$

Factor 3 Attributes/Indicators of Quality: Poor productivity of material and labour Q2 $=0.879$. Rework $\mathrm{Q} 3=0.881$. Appliances defects $\mathrm{Q} 4=0.829$

In the next stage is KMO and Bartlett's Test of the maximum likelihood factor analysis. The test shows the value of Chi-square, degree of Freedom (DF) and significance value $(\mathrm{P})$. With terms of significance close to zero obtained data as categories fit, and degrees of freedom having a positive value is considered good for proceed to the next testing.

As result of Factor Analysis, it provided KMO as 0.804 and Bartlett's Test of 191,863 and a significant result of 0,000 shows that the tested variable is eligible to be proceed to Confirmatory Factor Analysis (CFA). Stage SEM testing is modelling fit latent inter-relationship that has been in extracts so that a process of analysis such as CFA is carried out on every construct contained in the model, between endogenous constructs (independent) and between exogenous constructs (dependent). On modelling relationship between constructs exists (three) exogenous constructs (factor Resources, Quality, and Management) and (1) endogenous constructs (factor Delay). The CFA result on the construct yields 10 (ten) indicators that have a significant effect on project delays EPC LNG resulting in delay of $\mathrm{LNG}$ project.

\subsection{SEM Modelling Testing}

The SEM modelling test is done step by step overall through the overall model test (Overall model fit test) among others: Testing on the note for model. This test is performed to determine how fit the modelling with sample data already extracted through the process of factor analysis and then testing requirements Note for Model > level probabilities 0.05 shows fit model data and if the probability level $<0.05$ shows data modelling is not fit so it needs to be redo confirmatory factor analysis in order to obtain value significantly above 0.05 as to develop perfect constructs for exogenous and endogenous.

Tests fit model on AMOS obtained results Chi-Square $=104.061$, degrees of freedom DF: 63 and a probability level of 0.001 and also statement "Minimum was achieved" as shown in Figure 1 indicating that the process of further test can be carried out.
Figure 1 exhibits the result of SEM modelling regarding factors caused of delays in LNG projects. In Figure 2 that displays Chi-square value of 104.061 with $\mathrm{DF}=63$ and also shows the relationship value between independent endogenous variable constructs (Delay) and exogenous dependent (Management, Quality, Resources). Normality test data was carried out by using criteria ratio (CR) that shows the skewness value of \pm 2.58 at the 0.01 significance level. If the value critical ratio skewness value is less than the absolute value of 2.58 data can be said to have a normal distribution. The value of critical ratio skewness value all independent with dependent indicates the distribution value normal since it has a value less than 2.58 and the test of normality multivariate obtained CR value equal to 2.325 . Therefore the data has a univariate normal distribution as well multivariate.

Basic Factor Loadings Decision Making, provides the explanation as follows. If factor loading $>0.5$, then the relationship between constructs is considered strong. Otherwise the relationship between constructs is considered weak. The numbers in the "ESTIMATE" column show that the loadings factor of indicators of the associated construct. Relationship between constructs seen to be in the independent variable delay as well as there are 3 dependent variables namely variable management, resources, and quality. Relationships of three factor loadings in Figure 1 as would be described as follows.

1. The number 0.840 shows a strong number, the relationship between the indicators 'delay' and 'management' construct. Or it can be said that delay to an LNG project may be affected by management operational because it has a high loading factor as 0.840 .

2. The number 0.027 shows the weak number, the relationship between indicators 'delay' and 'construction resources'. Or it can be explained that delay to an LNG project is not influenced by factors 'resources' because it has a fairly low loading factor as only 0.027 .

3 . The figure of 0.542 shows a sufficiently strong number, the relationship between indicator 'delay' and 'quality' constructs. Or it can be explained that delays to an LNG project can be affected by a quality factor because it has a moderate loading factor as 0.542 .

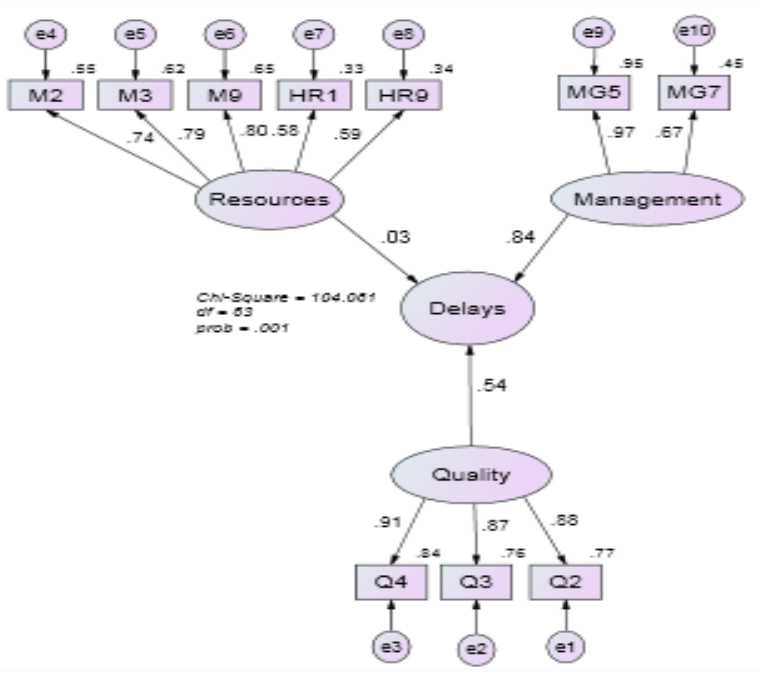

Fig. 1. SEM model for various constructs in the study 


\section{Conclusion and recommendation}

\subsection{Conclusion}

The dominant factors causing the lateness of LNG projects are overwhelming have a significant effect on the LNG project implementation particularly in the field of EPC MIGAS, which ultimately impacts on delays. From the analysis of the dominant factor of delay can be summed up as follows:

1. Indicators that have a significant effect on the dominant factor delays on Dependent variables are: a). Shortage of material in the market. b). Changes in material types and specifications during the construction. c). Damage sorted materials while they are needed urgently. d). Unavailability of experienced technical staff and scarcity of skilled labours. e). Unqualified work force team. f). Poor site management and supervision. g). Job assignment. h). Poor productivity of labour i). Rework. j). Appliances Defects.

2.Modelling Inter-Construct Structural Relationships with SEM Model showed that variable relationship between constructs indicating that the relationship that strong against the dominant factor of delays especially on the LNG project was management factor in which these factors play a role very important to the delay factor. As for the variable quality indicated a strong enough relationship. Variable resources indicated a weak relationship.

\subsection{Recommendation}

In order to anticipating the negative factor loading results suggested sample data of the respondents should more in number as suggested by of SEM software guidance for the sample adequacy $[15,16]$. For on-site problems faced by practitioners, results of this study were summarized as important points for solving delay problem in LNG projects as the following explanations. For management issues in the working field that should be carried out: a). Site condition meeting, intensive coordination between sub-contractors, share problems to main EPC contractor and owner. b). Top management must be solid to solve the interface work. c). High fundamental risk from the preparation and planning work has to be analysed, this must be good in achieving high progress. There should have a good team work to solve any problem with good communication. d). The best team between client, main EPC contractor and subcontractors should be solid. e).Strong on site leadership is needed.

For quality problem, the practitioners provided solutions with the following actions: a). Do the best working without any injuries and good in quality as suggested by Wise Global Training [26] and Khalique [27]. [b). Quality of the work to be checked frequently. c). Avoid any unaccepted condition due to poor quality of material, It needs to check spec and to discuss with on-site expert [28]. d). Check and recheck the quality procedure before installation to reduce rework as suggested by Levy and Civitello [29]. e). Procedure for installation is in top priority to be good service in quality. f). Best practices is should be record as it is useful for next time installation projects. This would result in less rework or no more rework. g). Finishing the project with in good quality procedure and double-checking before handover good performances. h). Quality Control must be applied on site continuously.

For future, factors such as design change as suggested by Kaming et.al [30] and financial factors related to delay advocated by Abdul-Rahman, et.al [10] could be considered in the model of delay analysis for LNG with EPC contract.

This research was sponsor with internal funding from Universitas Atma Jaya Yogyakarta (UAJY) through the Board of Research and Service. The authors were grateful to groups of the respondents participated throughout LNG projects in Indonesia, especial thanks to friends working at Donggi Senoro LNG projects. The authors of the research also thank for both Vice Rector of Academic Affair UAJY.

\section{References}

1. Asian Development Bank, Loan Indonesia: Tangguh Liquefied Natural Gas Project, Extended Annual Review Report, ADB (2012)

2. Nomura Research Institute, Study on Opportunities and Issues in introducing mini LNG facilities and equipment in Indonesia, www.meti.go.jp/meti_lib/report/ (2015)

3. Budisuanda, Advanced \& Effective Project Management (2017)

4. M.Z.A. Majid \& R. McCaffer. Factors of nonexcusable delays that influence contractors' performance, Journal of Management in Engineering, ASCE, pp. $42-49$ (1998)

5. A.M. Odeh. \& T.B. Hussien. Causes of Construction Delay: Traditional Contracts, Western Michigan University, Kalamazoo, USA (2002)

6. T.K. Soon. Dispute resolution in relation to delay of Construction projects, Master's project report submitted to faculty of Civil Engineering, Universiti Technology, Malaysia (2010)

7. M.M. Kumaraswamy, D.W.M Chan, Contributors to construction delays", CM \& E. Vol.16, p. 17-29 (1998)

8. A. Sugiharto \& K. Hampson, Identifying the important causes of Delays in building Construction Projects, Indonesia. Proceedings, 9th East AsiaPacific Conference on Structural Engineering and Construction, Bali, Indonesia. Accessed from: https://eprints.qut.edu.au/secure/00004156/01/Bali Conference_2003.doc (2003)

9. H. Doloi, A. Sawhney, \& K.C. Iyer. Structural equation model for investigating factors affecting delay in Indian construction projects, India (2012)

10. H. Abdul-Rahman, R. Takim, \& S.M. Wong, Financial-related causes contributing to project delays, Journal of Retail and Leisure Property. 8, 225-238. doi:10.1057/rlp.2009.11 (2009)

11. W. Alaghbari, M.R.A. Kadir, A. Salim, \& Ernawati, The significant factors causing delay of building construction projects in Malaysia, Engineering, 
Construction and Architectural Management Vol. 14 No. 2, 2007 pp. 192-206 q Emerald Group Publishing Limited 0969-9988

DOI 10.1108/09699980710731308 (2007)

12. R.B. Kline. Methodology in the social sciences. Principles and practice of structural equation modeling (2nd ed.). New York, NY, US: Guilford Press (2005)

13. D.L. Jackson, J.A.,Jr Gillaspy, \& R. PurcStephenson. Reporting practices in confirmatory factor analysis: An overview and some recommendations. Psychological Methods, 14(1), 623. http://dx.doi.org/10.1037/a0014694 (2009)

14. M.D.M. Islam \& O.O. Faniran, Structural equation model of project planning effectiveness, Con Mgmt \& $\quad$ Ecom 23(2):215-223 - February 2005 DOI: $10.1080 / 0144619042000301384$ (2005)

15. B.M. Byrne, Structural equation modeling with AMOS, (2nd ed.), New York: Routledge (2010)

16. S. Santoso. AMOS 22 untuk Struktural Equation modeling, Indonesia (2015)

17. D.A.R. Dolage \& D.LG. Rathnamali., Causes of Time Overrun in Construction Phase of Building Projects A Case Study on Department of Engineering Services of Sabaragamuwa Provincial Council, The Institution of Engineers, Sri Lanka (2013)

18. S. Shanmugapriya, \& K. Subramanian, Investigation of Significant Factors Influencing Time and Cost Overruns in Indian Construction Projects, India (2013)

19. V. Parath, S.M. Renuka, and U. Gunasekaran. 2012, Causes of Delay in Indian Construction Industry, Applied Mechanics and Materials, Vols. 174-177 pp 2774-2777. DOI10.4028/www.scientific.net/

20. M. Haseeb, Xinhai-Lu, A. Bibi, Maloof-ud-Dyian, W. Rabbani, Problems of projects and effects of delays in the construction industry of Pakistan, Pakistan (2011)

21. S.C. Chai, \& A.M. Yusof, SEM Approach: Reclassifying Housing Delay in Malaysian Housing Industry, Malaysia. Journal of Economics and Business Management, 3(3) March 364-369, DOI: 10.7763/JOEBM.2015.V3.211 (2015)

22. M. Garbharran, J. Govender, \& T. Msani, Critical successful factors influencing project success in the construction industry, Acta Structilia 19(2) 90-109 (2012)

23. H. Doloi, A. Sawhney, \& K.C. Iyer. Structural equation model for investigating factors affecting delay in Indian construction projects, India (2012)

24. H. Doloi. Understanding Impacts of Time and Cost Related Construction Risks on Operational Performance of PPP projects, International of Strategic Property Management, 16 (3) 316-337 doi.org/10.3846/1648715X.2012.688774| (2012)

25. J.B. Yang \& SF Ou. Using structural equation modelling to analyse relationships among key causes of delay in construction, Canada (2008)

26. Wise Global Training. Introduction to Oil and Gas Operational Safety, Revision Guide for the NEBOSH International Technical Sertificate in Oil and Gas Operational Safety, Routledge (2015)
27. A. Khalique, Basic Offshore Safety: Safety induction and emergency training for new entrants to the offshore Oil and Gas Industry, Routledge (2016)

28. P. Christensen, \& L.R. Dysert. AACE International Recommended Practice No. 18R-97, Cost Estimate Classification System - As Applied in Engineering, Procurement, and Construction for the Process Industries TCM Framework: 7.3 - Cost Estimating and Budgeting, AACE International (2005)

29. S.M. Levy and A.M. Civitello. Construction Operations Manual: Policies and Procedures, 5th ed. McGrawHill (2014)

30. P.F. Kaming, P.O. Olomolaiye, G.D. Hold, \& F.C. Harris. Factors influencing construction time and cost overruns on high-rise projects in Indonesia, Construction Management \& Economics. Jan1997, Vol. 15 Issue 1, p83-94. 12p. 14 Charts. DOI: 10.1080/014461997373132. (1997) 